\title{
The sensitivity of global surface air temperature to vegetation greenness
}

\author{
Xiuliang Yuan ${ }^{1, *}$, Rafiq Hamdi ${ }^{2,3,4}$, Friday Uchenna Ochege ${ }^{3,5,6}$, Alishir Kurban ${ }^{3,7}$, \\ Philippe De Maeyer ${ }^{1,3,7}$
}

${ }^{1}$ Department of Geography, Ghent University, Ghent 9000, Belgium.

${ }^{2}$ Royal Meteorological Institute, Brussels 1180, Belgium.

${ }^{3}$ State Key Laboratory of Desert and Oasis Ecology, Xinjiang Institute of Ecology and Geography, Chinese Academy of Sciences, Urumqi 830011, China.

${ }^{4}$ Department of Physics and Astronomy, Ghent University, Ghent 9000, Belgium

${ }^{5}$ University of Chinese Academy of Sciences, Beijing 100039, China.

${ }^{6}$ Department of Geography and Environmental Management, University of Port Harcourt, Choba 5323, Nigeria.

${ }^{7}$ Sino-Belgian Joint Laboratory for Geo-information, Urumqi 830011, China and Gent 9000, Belgium

\section{* Corresponding author:}

Xiuliang Yuan

Department of Geography, Ghent University

Campus Sterre, building S8, Krijgslaan 281, B-9000 Ghent, Belgium

Email: xiuliang.yuan@ugent.be

This article has been accepted for publication and undergone full peer review but has not been through the copyediting, typesetting, pagination and proofreading process which may lead to differences between this version and the Version of Record. Please cite this article as doi: $10.1002 /$ joc. 6633 


\begin{abstract}
Terrestrial vegetation plays a crucial role in governing the land surface energy budget, which in turn drives the climate of the Earth. The climatic feedbacks of vegetation changes are different across vegetation greenness gradients and climatological conditions, which has not been studied clearly. In this study, we used remote sensing and re-analysis datasets to investigate global climatic feedbacks of vegetation changes on the surface air temperature (SAT). The Common Land Model (CoLM) was also used to reproduce land-atmosphere energy processes and to explain the climatic feedbacks based on the biophysical mechanisms. Our results show that the sensitivity of SAT to the increase in vegetation greenness presents a convergent relationship. The sign and magnitude of the sensitivity are determined by the background climate conditions. The convergence sensitivity is regulated by the corresponding variations of satelliteobserved evapotranspiration (ET) and albedo, and the associated partitioning of surface energy between sensible and latent heat fluxes simulated by the CoLM. The exploration of the global climatic feedbacks of vegetation changes in this work will be helpful to identify future climate change required for the development of appropriate strategies for mitigating global warming.
\end{abstract}

Key words: Terrestrial vegetation; Climatic feedbacks; Common Land Model; Global warming 


\section{Introduction}

Terrestrial vegetation is an essential and indispensable constituent of the climate system, which exerts climatic feedbacks by changing surface characteristics of the Earth and associated surface processes (Klein et al., 2017; Richardson et al., 2013; Woodward et al., 1998). In particular, terrestrial vegetation can modulate surface air temperature (SAT) by changing canopy roughness that could regulate the vapor and heat exchanges between the land surface and the atmosphere (Jing and $\mathrm{Li}, 2016$ ), or by changing surface albedo and evapotranspiration (ET) which governs the Earth's radiation budget (Zhang et al., 2013; Ge et al., 2014). Therefore, understanding the climatic feedbacks of vegetation changes would be valuable for deepening the perception of global climate change.

During the past decades, the widespread interannual greening of the Earth has been documented using satellite observations and model simulations at both regional and continental scales (Zhu et al., 2016), such as in temperate and boreal Eurasia (Piao et al., 2011; Mao et al., 2016), east and central Asia (Peng et al., 2011; Zhou et al., 2015), North America (Wang et al., 2011) and Atacama desert in South America (He et al., 2017), etc. This greening of the Earth virtually increased the carbon sequestration via the biomass (Pan et al., 2011), potentially considered as the key instrument to mitigate the climate change (Canadell and Raupach, 2008). Yet, the benefit of the increased vegetation capability to absorb anthropogenic carbon dioxide emissions on the climate could be either enhanced or compensated by biophysical mechanisms (Anderson et al., 2011; Bala et al., 2007; Field et al., 2007; Li et al., 2015; Zeng et al., 2017). Biophysical effects (e.g., albedo, ET) (Pearson et al., 2013; Shen et al., 2015) induced by modulating the land-atmosphere fluxes of energy and vapor are more complicated than the biochemical (e.g., carbon cycle) effects because of their high spatial heterogeneity. The impacts generated by the ongoing greening of the Earth still remain a major challenge in current climate research.

Surface albedo and ET are two important vegetation characteristics that govern the partitioning of land surface radiation between latent, sensible, and ground heat fluxes, which in turn drives the climate of the Earth. Changes in opposite strengths between the biophysical effects of the albedo-induced warming and the ET-induced cooling associated with the vegetation greening may lead to variability in SAT (Alkama and Cescatti, 2016; Peng et al., 
2014). For some regions, the differences between both contributions are so small that scientists often draw opposite conclusions due to different input variables (e.g., land surface temperature, surface air temperature) or methods (e.g., climate model, remote sensing). For example, some studies reported that temperate forests in the middle latitudes of the northern hemisphere induce warming effects (Lee et al., 2011; Zhang et al., 2014), while other studies indicate cooling effects (Li et al., 2015; Wickham et al., 2012). In addition to being affected by vegetation, the SAT is also affected by other factors. For example, it is well recognized that remote oceanic conditions may be the dominant driver of interannual variations of global SAT through the teleconnection (Hu and Fedorov, 2017; England et al., 2014). Besides, the impacts of changes in greenhouse gas and aerosol on SAT have also been mostly debated in previous studies (Solomon et al., 2011; Jeong et al., 2010). Yet, it is still unclear how the recent Earth's greening affects the SAT anomalies at a global scale. Therefore, isolating these external climate signals from climatic feedbacks of vegetation changes is required in future research.

Great efforts have been devoted on assessing the potential climatic effects of vegetation changes on surface temperature at both global and regional scales over the past several decades (Forzieri et al., 2017; Yu et al., 2018). Some studies have indicated that tropical afforestation activities can mitigate warming due to their dominant strength of evaporative cooling (Bonan, 2008; Li et al., 2015). In boreal forests, the vegetation greening has the ability to produce a positive feedback to the warming by masking the high reflectance of snow (Bonan et al., 1992; Pearson et al., 2013). In Europe, the afforestation has led to an increase of 0.12 Kelvin in warming during summertime, mainly due to greenhouse gas emissions through species conversion (Naudts et al., 2016). In contrast, in China, afforestation/reforestation programmes have been implemented as a constructive strategy to attenuate local warming (Jiang et al., 2015; Peng et al., 2014). Based on the above studies, the climatic feedbacks of vegetation change are divergent with respect to different geographical and background climatological conditions.

Besides, vegetation-climate feedbacks differ across the land cover types with different greenness. For example, Zhao and Jackson (2014) reported that the replacement of cropland with deciduous broadleaf forests tends to cool near-surface air, while evergreen needle leaf forests tend to warm the air in North America. Based on idealized model simulations, Gibbard et al. (2005) indicated that a global replacement of current vegetation by trees would result in a global mean warming of $1.3{ }^{\circ} \mathrm{C}$, while replacement by grasslands would lead to a cooling of $0.4{ }^{\circ} \mathrm{C}$. 
Greater attention in most previous studies are devoted to individual biomes (e.g., forests with large greenness), while few studies have focused on other land cover types with a lower greenness (e.g., short vegetation). Since focusing on a single type of vegetation, especially forests, does not sufficiently represent the characteristics of terrestrial ecosystems (Loranty et al., 2014), climatic feedbacks of vegetation changes under various vegetation greenness should be quantified.

This study aims to investigate the impacts of vegetation changes on SAT across various vegetation greenness and background climatological conditions. In order to overcome the limits and uncertainties that existed in previous assessments, a principal component regression analysis was used to disentangle external climate signals from SAT. Another focus of this study is that a land surface model was used to reproduce the energy processes to further explain the variations and the changes in climatic feedbacks of vegetation changes. This study is expected to provide a globally robust and data-driven evaluation of the biophysical impacts of vegetation feedbacks on the SAT.

\section{Materials and Methods}

\subsection{Vegetation and climate datasets}

Remotely sensed leaf area index (LAI) and Normalized Difference Vegetation Index (NDVI) provide quantitative information of vegetation coverage, productivity and greenness, and have been widely used to monitor vegetation growth (Zhu et al., 2016; Forzieri et al., 2017). The Global Inventory Modeling and Mapping Studies (GIMMS) LAI3g and NDVI3g datasets with a 1/12 degree spatial resolution and a half-month time-step from January 1982 to December 2015 were used in this study to indicate the vegetation greenness of the Earth. The GIMMS LAI3g dataset was constructed from the Advanced Very High Resolution Radiometer (AVHRR) Normalized Difference Vegetation Index (NDVI) dataset, together with the Moderate Resolution Imaging Spectroradiometer (MODIS) LAI dataset by using artificial neural network (ANN) models (Zhu et al., 2013). The quality of GIMMS LAI3g dataset has been evaluated by comparison with field measurements, intercomparison with other existing alternative satellite products, which provides a high applicability in studies of monitoring vegetation activities (Wu et al., 2017; Yuan et al., 2015; Zhu et al., 2017). The cells with mean annual NDVI values of less 
than 0.08 were discarded to avoid the effects of unvegetated regions. To match with climate data, the raw LAI3g and NDVI3g data were simply averaged onto a $2.0^{\circ} \times 2.0^{\circ}$ grid.

The gridded monthly average daily mean, maximum, minimum SAT ( $\mathrm{T}_{\text {mean }}, \mathrm{T}_{\max }$ and $\mathrm{T}_{\min }$ ), as well as the precipitation datasets with a spatial resolution of $0.5^{\circ}$ during $1982-2015$ were obtained from the Climate Research Unit (CRU; TS4.01); the datasets were constructed by the University of East Anglia (Harris et al., 2014). The monthly mean solar radiation data (SR) from 1982 to 2015 was obtained from NCEP/NCAR Reanalysis products (Kalnay et al., 1996). The CRU and SR datasets were simply averaged onto the $2.0^{\circ}$ grid. A global 6-hourly, $0.5^{\circ}$ climate dataset, including downward short- and long-wave solar radiation, temperature, precipitation, specific humidity, surface air pressure and wind speed variables were obtained from Princeton University (Sheffield et al., 2006). The Princeton climate dataset provides a long-term (19502015) globally consistent dataset of near-surface meteorological forcings that can be used to drive the land surface models. A global gridded monthly dataset of terrestrial ET with a spatial resolution of $0.25^{\circ}$, calculated based on the Global Land Evaporation Amsterdam Model (GLEAM V3.2a) was used in this study (Martens et al., 2017; Miralles et al., 2011). The GLEAM V3 ET dataset has several improvements, new data assimilation scheme, updated water-balance module, as well as updated evaporative stress functions, which has a huge potential for recovering information about ET from the available data stack of climatic and environmental observations from space. Another ET dataset was used from Jung et al. (2010). This dataset was produced by using Model Tree Ensembles (MTE) to combine observations from both flux-tower ET and remote sensing data. The second edition of monthly CLARA ("The CM SAF cLoud, Albedo and surface RAdiation dataset from AVHRR data" - second edition denoted CLARA-A2) surface albedo dataset was used in this study because of its long-term records, providing the overlap period (1982-2015) with the datasets of LAI and climate variables (Karlsson et al., 2017). This dataset that was obtained from AVHRR instruments with a spatial resolution of $0.25^{\circ}$, and has been validated against a large number of in-situ reference data, covering both vegetated regions and snow/ice-covered areas. The MODIS monthly average snow fraction dataset at $0.05^{\circ}$ during 2001-2015 (MOD10C1) was obtained from NASA National Snow and Ice Data Center (https://nsidc.org/). The low-quality pixels were first filtered by the Quality Control (QC) layers. Afterwards, the dataset was averaged onto $2.0^{\circ} \times 2.0^{\circ}$ to match climate dataset. 
Studies have shown that global temperature changes are tied to the natural climate variability (Kosaka and Xie, 2013; Schmidt et al., 2014). In this study, the El Niño-Southern Oscillation (ENSO) (Pan and Oort, 1983) and Atlantic Multidecadal Oscillation (AMO) (Liu, 2012) indices were used to represent the natural climate fluctuations which took place in the tropical Pacific Ocean and the North Atlantic Ocean, respectively. These two oscillation indices were chosen because of their popularity, which have demonstrated a significant contribution to the global climate variability studies. ENSO is a periodic oscillation (2-7 years) of wind and sea surface temperatures (SST) occurring in the eastern equatorial Pacific, which is very tightly regulated by vertical energy convergence and contributes to the global climate change through atmospheric teleconnections ( $\mathrm{Hu}$ and Fedorov, 2017). The ENSO index was described as the SST anomaly averages within the equatorial Pacific domain between $160^{\circ} \mathrm{E}-90^{\circ} \mathrm{W}$ and $5^{\circ} \mathrm{S}-5^{\circ} \mathrm{N}$ based on the HadISST1 dataset (Rayner et al., 2003). AMO is identified as a climate oscillation occurring in the North Atlantic Ocean with an estimated period of 60-80 years (McCarthy et al., 2015), which has also proven to be closely linked to global temperature and precipitation, particularly in the Northern Hemisphere (Zampieri et al., 2017). The AMO index (detrended and smoothed) was described as the North Atlantic monthly SST anomaly averages over $0^{\circ}-70^{\circ} \mathrm{N}$ based on the HadISST1 dataset in this study (Enfield et al., 2001). The ENSO and AMO index were obtained from the National Oceanographic and Atmospheric Administration (NOAA) Earth System Research Laboratory (ESRL) (https://www.esrl.noaa.gov/).

For the $\mathrm{CO}_{2}$ concentrations, the global monthly mean estimates were obtained from the NOAA/ESRL website (https://www.esrl.noaa.gov/gmd/ccgg/trends/data.html), available from 1980. The dataset was calculated based on approximately 40 marine boundary layer (MBL) sites from the NOAA/ESRL flask network, and the reported uncertainty is only $0.13 \mathrm{ppm} / \mathrm{month}$ evaluated by using a monte carlo technique (Ballantyne et al., 2012). To account for the stratospheric aerosol changes, we employed a global gridded monthly mean stratospheric aerosol optical depth (AOD) dataset (MERRA-2) spanning 1982-2015, from NASA Goddard Earth Sciences (GES) Data and Information Services Center (DISC) (https://disc.gsfc.nasa.gov) (GMAO, 2015).

\subsection{Common Land Model}


The Common Land Model (CoLM) (Dai et al., 2003) was used in this study to investigate the impacts of vegetation changes on land surface energy budget. CoLM is a process-based land surface model that allows to simulate the interactions between the atmosphere and the land, including representations of water, carbon, and energy processes. CoLM combines the best features of three existing successful land models: the Land Surface Model (LSM) (Bonan, 1996), the Biosphere-Atmosphere Transfer Scheme (BATS) (Dickinson et al., 1993), and the 1994 version of the Chinese Academy of Sciences Institute of Atmospheric Physics LSM (IAP94) (Dai and Zeng, 1997), which was originally developed for providing a land component for climate models.

In CoLM, the vegetation is regarded as one canopy layer with two kinds of leaves: sunlit and shaded leaves. The solar radiation flux absorbed by vegetation depends on the sum of sunlit and shaded leaves. Furthermore, LAI is a crucial variable in determining the fractional area of sunlit leaves that decreases exponentially with the cumulative LAI from the canopy top, and thus LAI is an important parameter in determining canopy energy budget. Besides, the transpiration of vegetation at canopy level, prescribed in CoLM depends on the canopy stomata conductance which was scaled up from leaf to canopy through the intermediate variable LAI. On the whole, the temporal variations in the exchanges of energy and vapor between land and atmosphere are largely determined by variations in LAI. In this study, the satellite-observed LAI is integrated into CoLM to represent the vegetation changes.

\subsection{Statistical analyses}

To quantify the global interannual sensitivities (i.e., the regression coefficients) of SAT to vegetation changes, we used the principal component regression (PCR) (Jolliffe, 1982) to perform analysis for each pixel. PCR has proven to be an effective method that can reduce the collinearity between independent variables required for obtaining a robust estimation of the regression coefficients (Seddon et al., 2016). The principal component analysis was first used to extract orthogonal variables and corresponding coefficients from independent variables:

$$
\left[t_{1}, t_{2}, t_{3}, \ldots, t_{n}\right]^{T}\left[z_{1}, z_{2}, z_{3}, \ldots, z_{n}\right]=\left[v_{1}, v_{2}, v_{3}, \ldots, v_{n}\right]
$$


where $\mathrm{Z}$ is the independent variables (i.e., $\mathrm{CO}_{2}$, LAI, AMO, ENSO, AOD, precipitation, $\mathrm{SW}) ; \mathrm{n}$ is the numbers of independent variables; $\mathrm{v}$ and $\mathrm{t}$ are the orthogonal variables and corresponding coefficients. All variables were linearly detrended prior to the PCR analysis to avoid autocorrelation between variables. Then, the orthogonal variables were selected to perform multiple linear regression:

$$
\begin{aligned}
Y & =a_{1} v_{1}+a_{2} v_{2}+a_{3} v_{3}+\cdots+a_{n} v_{n}+\varepsilon \\
& =\left[a_{1}, a_{2}, a_{3}, \ldots, a_{n}\right]\left[t_{1}, t_{2}, t_{3}, \ldots, t_{n}\right]^{T}\left[z_{1}, z_{2}, z_{3}, \ldots, z_{n}\right]+\varepsilon
\end{aligned}
$$

where $Y$ is the independent variable (i.e., SAT); $\left[a_{1}, a_{2}, a_{3}, \ldots, a_{n}\right]\left[t_{1}, t_{2}, t_{3}, \ldots, t_{n}\right]^{T}$ is the terminal regression coefficient vector which was calculated from extracted orthogonal variables, and $\varepsilon$ is the residual error. Note that only the coefficients of multiple linear regression with the significant level of $p<0.05$ was used to calculate the terminal regression coefficients.

To reveal the effects of vegetation changes on surface energy budget, we designed a sensitivity experiment in CoLM by using Morris (1991) method which provides a qualitative assessment of each parameter to model outputs. For the sensitivity experiment, the mean satellite-derived LAI values from 1982 to 2015 were used to replace model defaults. The variant values of LAI was constrained to its $30 \%$ original values [70\% LAI, $130 \% \mathrm{LAI}$ ] to avoid the abnormal outputs. For parameter LAI, we calculated its effects on output as

$$
\mathrm{E}_{i}=\frac{f\left(p_{1}, p_{2}, \ldots, p_{i}+\Delta, \ldots, p_{k}\right)-f\left(p_{1}, p_{2}, \ldots, p_{i}, \ldots, p_{k}\right)}{\Delta}
$$

where $\Delta$ is the step size of an input parameter $\left(p_{i}\right)$. In this experiment, only satellite-derived LAI was changed, while other parameters were fixed at the default values. $\Delta$ is equal to $\mathrm{j} / 2(\mathrm{j}-1)$ (Campolongo et al., 2007), and $\mathrm{j}$ is the sampling levels which is predefined as 5 in this study. $\mathrm{E}_{i}$ is the model output. The initial LAI value was randomly selected, and vary by $\Delta$. This is repeated $r$ times ( $r$ trajectories where $r=10$ in this study). Then, the overall sensitivity of vegetation changes on surface energy budget $(u)$ was calculated as

$$
\mathrm{u}=\frac{\sum_{\mathrm{i}=1}^{\mathrm{r}} \mathrm{E}_{\mathrm{i}}}{r}
$$

To reveal how the background climate conditions affect the climatic sensitivity, we reclassified the Earth into nine climate zones based on Köppen-Geiger method (Kottek et al., 2006). Seven climate classifications were defined according to Zhou and Wang (2016), including 
polar tundra, cold humid, cold winter dry, cold summer dry, temperature humid, temperate arid, and arid climates. Equatorial and frost climates were added in this study (Figure S1). The frost climate was not analyzed because there are no vegetated pixels.

\section{Results}

\subsection{Sensitivities of SAT to vegetation greenness}

Most regions of the Earth are experiencing a trend of vegetation greening, indicated by both satellites retrieved LAI and NDVI (Figure S2). For LAI, 50\% of the grid cells show an increasing trend significantly $(p<0.05)$, while only $8 \%$ of the grid cells show a decreasing trend significantly. For NDVI, $23 \%$ of the grid cells show significant increasing trends, while $15 \%$ of the grid cells show a significant decreasing trend. To determine how the vegetation greening influences SAT, we first used the coefficients of PCR to assess the sensitivities of SAT to LAI variations (Figure 1). The spatial patterns of $\mathrm{T}_{\text {mean }}$ sensitivities show that LAI-related warming effect occurs over the Arctic tundra and boreal forest belts in the high-latitudes of the northern hemisphere. In contrast, the cooling effect occurs in mid-latitudes of the northern hemisphere and southern hemisphere, with hotspots in the drylands of the Sahel, Central Asia, Western Australian, Southwest North America, and the Middle East (Figure 1(c)). The LAI-climate feedbacks are not uniformly symmetrical between the northern and southern hemispheres. There

is more warming near the North Pole, slight cooling near the equator, and larger cooling near the mid-latitudes (Figure 1(d)). Both $\mathrm{T}_{\max }$ and $\mathrm{T}_{\min }$ sensitivities show similar spatial patterns with $\mathrm{T}_{\text {mean }}$. However, the magnitude of the sensitivities differs among them. The $\mathrm{T}_{\text {mean }}$ sensitivities lie within the range between $T_{\max }$ and $\mathrm{T}_{\min }$. Compared to $\mathrm{T}_{\min }$, the $\mathrm{T}_{\max }$ sensitivities are slightly larger in the mid-latitudes in both hemispheres $\left(20^{\circ} \mathrm{N}-40^{\circ} \mathrm{N}\right.$ and $\left.20^{\circ} \mathrm{S}-40^{\circ} \mathrm{S}\right)$ and in the northern high-latitudes $\left(>40^{\circ} \mathrm{N}\right)$. However, there is almost no difference between them near the equator and in the southern high-latitudes $\left(>40^{\circ} \mathrm{S}\right)$. Further, these sensitivity patterns are robust when the NDVI is used instead of LAI as an indicator of vegetation greenness (Figure S3).

Additionally, we hypothesized that different vegetation greenness gradients, such as low greenness areas in desert ecosystems and high greenness areas in forest ecosystems, may likely have different effects on SAT. Thus, we further assessed the temperature sensitivity across LAI 
gradients (Figure 2(a)). A significant decreasing trend of sensitivities of $T_{\text {mean }}$ to LAI was determined. It indicated that the magnitudes of temperature sensitivities for a given quantity of LAI, decreased along with an increase of LAI with convergence to a value of zero. The occurrence of such a convergent pattern is explained in our exponential regression analysis. Moreover, both $\mathrm{T}_{\max }$ and $\mathrm{T}_{\min }$ also show the similar convergent pattern (Figure S4).

Given that the climatic sensitivity might be determined by the background climate conditions, we further analyzed the sensitivity in different climate zones to see if the sensitivity is really convergent as the greenness increases (Figure 2(b)). The results show that the sign and magnitude of the $\mathrm{T}_{\text {mean }}$ sensitivity are determined by the background climate conditions. For example, the average sensitivity is negative in the arid regions, temperate arid, and equatorial climate zones. In temperate humid, cold summer dry, cold winter dry, cold humid, and polar tundra climate zones, the sensitivity is positive. Besides, the notable monotonically decreasing pattern of the sensitivity values is observed with convergence to a value of zero across almost eight climate zones (Figure 3). The similar patterns in different climate conditions are also found for $\mathrm{T}_{\max }$ and $\mathrm{T}_{\min }$ (Figure $\mathrm{S} 4, \mathrm{~S} 5$ and $\mathrm{S} 6$ ). Obviously, the sensitivity convergence exists as the greenness increases, although the convergence becomes weak in some climate zones, for example in cold summer dry and polar tundra zones.

\subsection{Controls of biophysical factors on climate sensitivity}

Both ET and albedo are two critical biophysical factors in influencing surface energy budget which largely in turn contributes to climatic feedbacks. Vegetation with higher greenness generally depicts lower albedo, potentially leading to a warming effect as a result of large radiation absorbance. However, the extra energy could be dissipated by increasing canopy ET. The mechanism behind the climatic sensitivity of vegetation greenness changes is further analyzed by statistical methods and sensitivity experiments by numerical simulations. First, a linear regression analysis in which the ET or albedo is set as dependent variable and LAI is set as an independent variable was performed. The slope of the linear regression is defined as the sensitivity of ET ( $\triangle \mathrm{ET} / \triangle \mathrm{LAI})$ or albedo ( $\triangle$ albedo/ $\triangle \mathrm{LAI})$ to LAI. The results show that both ET and albedo exhibit a convergent trend to changes in vegetation greenness with higher $\triangle \mathrm{ET} / \triangle \mathrm{LAI}$ and $\triangle$ albedo/ $\triangle \mathrm{LAI}$ values in low vegetation greenness areas and lower values in 
highly vegetated areas (Figure 4). This convergent is robust to different ET datasets used (i.e., GLEAM ET and MTE ET).

To further determine the extent to which the climatic sensitivity is correlated with biophysical factors (i.e., albedo and ET) in different climate zones, we analyzed the partial correlation coefficients between the climatic sensitivity and sensitivity of ET/albedo to vegetation (i.e., $\triangle \mathrm{ET} / \triangle \mathrm{LAI}$ and $\triangle$ albedo/ $\triangle \mathrm{LAI}$ ). This procedure can remove the cofounding effect between ET and albedo. The results show that both $\triangle \mathrm{ET} / \triangle \mathrm{LAI}$ and $\triangle$ albedo/ $\triangle \mathrm{LAI}$ are significantly correlated with the $\mathrm{T}_{\text {mean }}$ sensitivities, but they play a contrasting role in determining climatic sensitivity that $\triangle \mathrm{ET} / \triangle$ LAI has a positive correlation while $\triangle$ albedo $\triangle \triangle$ LAI have a negative correlation in most climate zones, such as in cold humid, cold summer dry, cold winner dry, polar tundra and temperate humid climate zones. However, this contrasting correlation is reversed in the arid region and equatorial climate zones. The different ET datasets show a robust correlation pattern, except in cold winter dry climate zone where MET ET is positively correlated with climate sensitivity significantly $(p<0.01)$, while GLEAM ET is negatively correlated with climatic sensitivity, but not significantly. The magnitude of the correlation is different when different ET datasets were used. MTE ET has a higher correlation coefficient with climatic sensitivity than the GLEAM ET, except in the arid region and temperate arid climate zones. $\mathrm{T}_{\max }$ and $\mathrm{T}_{\min }$ show similar patterns in the correlation coefficients between climatic sensitivity and sensitivity of ET/albedo to vegetation. However, in the arid region where the $\mathrm{T}_{\max }$ sensitivities are found to be negatively correlated with $\triangle \mathrm{ET} / \triangle \mathrm{LAI}$, the $\mathrm{T}_{\min }$ sensitivities are not significantly correlated with $\triangle \mathrm{ET} / \triangle \mathrm{LAI}$ (Figure S7).

Next, a sensitivity experiment was designed to simulate the partitioning of energy fluxes between the land surface and the atmosphere by using CoLM (See methods). As shown in Figure 5 , the surface energy budget exhibits considerable variations in an association with an increment of LAI. The radiation increased near the Arctic, central and eastern Asia, but reduced in the middle belt of Eurasia, western North America and Austria. Generally, the spatial variation characteristics of latent heat flux (Qle) and sensible heat flux (Qh) are basically similar, but the sign is opposite because they are two different ways of dissipating heat. However, the changes in ground heat flux $(\mathrm{G})$ show a very small fluctuation. In the boreal regions, the increases in LAI are associated with a decrease in Qle, but an enhancement in Qh, and the decrease of QLe 
exceeds the decrease of Rnet (Figure 6(a)), which potentially leads to surface warming. This is consistent with the positive sensitivity of SAT to LAI in this region (Figure 1(a-c)). By contrast, in the mid-latitudes, the strength of Qh-induced warming decreased, while the strength of Qleinduced cooling increased, which causes a net cooling effect. This is more evident in arid regions, such as Western America, Central Asia and Western Austria. In the equatorial regions, there are quite small changes in both Qle and Qh, and thus a small net energy change. And this is consistent with a relatively stable climatic sensitivity in this region. The difference between Rnet and Qle $(\triangle($ Rnet-Qle $) / \triangle$ LAI) was further analyzed across vegetation greenness (Figure 6(b)). The results also show that $\triangle$ (Rnet-Qle)/ $\triangle$ LAI reveals a significant convergent trend associated with an increase in the LAI. LAI changes lead to a larger variation of $\triangle$ (Rnet-Qle)/ $\triangle$ LAI in magnitude in lower greenness regions, and a lower variation in higher greenness regions. These results indicate that the climatic sensitivity of vegetation greenness changes, to a large extent is largely governed by the associated changes in the local energy budget.

We further analyzed how the $\triangle($ Rnet-Qle) $/ \triangle$ LAI varies in different climatic regions. In arid region and temperate arid climate zones, the increased latent energy flux exceeds the net radiation, which causes a cooling effect, while in temperate humid, cold summer dry, cold winter dry, and cold humid climate zones, the net radiation exceeds the latent energy flux, resulting in a warming effect. These changes in the energy fluxes further support the results of the sensitivity analysis in Figure 2(d). However, the $\triangle$ (Rnet-Qle)/ $\triangle$ LAI changes suggest a cooling effect and Warming effect in polar tundra and equatorial climate zones, respectively, which do not agree well with the results of the sensitivity analysis. The potential causes are discussed in the discussion section.

\section{Discussion}

The widespread greening has been reported over the global vegetated area (Zhu et al., 2016), which has a profound impact on the current climate change (Zeng et al., 2017; Yuan et al., 2017). The biophysical effects of vegetation on SAT presented in this study show that more warming occurs near the North Pole, slight cooling near the equator, and larger cooling near the midlatitudes. The latitudinal patterns are consist with previous satellite-based analysis using land 
surface temperature (Forzieri et al., 2017). However, we also found a discrepancy in tropical forests near the equatorial regions between $10^{\circ} \mathrm{N}-10^{\circ} \mathrm{S}$ compared with previous studies ( $\mathrm{Li}$ et al., 2015; Snyder et al., 2004; Winckler et al., 2019; Dickinson and Henderson-Sellers, 1988). All these studies found a stronger cooling effect near the equatorial regions than our analysis that indicates a mild cooling effect (Figure 2(b)). These studies usually adopted climate models by changing one land cover type to another or analogous methods which compare climatic conditions between forest areas and adjacent non-forest areas. These methods are based on a complete land cover transition (i.e. 100\%), which could not reflect actual changes in vegetation. Therefore, a satellite-based changes in vegetation greenness (indicated by LAI) in this study would realistically lead to a smaller biophysical effect. However, our study didn't consider the land cover change, which may also lead to a discrepancy for this region. Both LAI and land cover change should be considered together in the future studies.

Given the differences in vegetation greenness from low values in desert ecosystems to high values in tropical forest ecosystems, we hypothesized that climate feedbacks vary significantly. Two important vegetation characteristics, ET and albedo, as well as associated energy processes, are important factors in driving climate change. These were used in this study to explain the climatic feedbacks based on their biophysical mechanisms. We found that the SAT shows higher sensitivity to LAI changes in the lower greenness regions than in the higher greenness regions. A monotonic convergent-shaped pattern for the sensitivity values was determined in this study, and the convergent sensitivity is robust in different climate zones. These results suggest that under the background that global greenness increases, the climatic sensitivity is getting weak.

We used ET and albedo to explain the climatic sensitivity changes because they are the critical factors in altering surface energy budget, which in turn drive the SAT change. Both ET and albedo exhibit higher sensitivity to LAI changes in low vegetation greenness areas compared to high vegetation greenness areas. The findings imply that the climatic feedbacks of vegetation greening to a large extent are dominated by biophysical processes. The high sensitivity of both ET and albedo to LAI in lower greenness regions could cause large fluctuations in energy partitioning between the atmosphere and the land surface. It is well known that the proportion of dissipated energy via ET is truncated in lower greenness regions because of the less availability of leaf area to enhance transpiration (Brun et al., 1972). Hence, a larger proportion of energy is 
released through the form of sensible heat, which can directly cause surface temperature changes. Furthermore, without large water vapor from ET, fewer clouds will be formed (Peng et al., 2014). As a result, inadequate mitigation effects from attenuating sunlight and long-wave radiation released from clouds may lead to energy deficits in lower greenness regions, which can result to large fluctuations in temperature. This gives reason for the higher variations in Qh and Qle in the lower greenness regions compared to higher greenness regions. The findings are validated by the CoLM simulations that changes in LAI in lower greenness regions have a higher potential for influencing land surface energy budgets.

As vegetation greenness increased, the extra energy absorbed by vegetation is offset by a greater latent heat loss. Both Qh and Qle show smaller fluctuations, which in turn contributes to less variation range in SAT. Besides, both albedo and ET show smaller variations in higher greenness areas. The biophysical effects (ET-induced cooling versus albedo-induced warming) present comparable strengths that weaken their net effects, thereby, leading to a stable temperature status. Therefore, a cooling or warming effect is determined by the relative strength between ET-induced cooling and albedo-induced warming without consideration of other factors such as land cover change, land-atmosphere interactions, atmospheric circulation, etc. The result is consistent with the study of Li et al. (2015) which reported that biophysical effects between ET and albedo can be offset by each other in forest regions with high greenness between $35^{\circ} \mathrm{N}$ and $45^{\circ} \mathrm{N}$. Besides, this study is also comparable to the work of Zhao and Jackson (2014) which indicated that evergreen needle leaf and deciduous broadleaf forests have smaller LST ranges than adjacent croplands or grasslands across North America. Additionally, Peng et al. (2014) also determined that planted forests have a smaller magnitude of LST changes than adjacent croplands or grasslands in China. All these results suggest that vegetation feedbacks have higher variability in low greenness regions than those in the high greenness regions.

In this study, we conducted an assessment of climatic sensitivity of vegetation changes on the SAT under different climatological conditions. The background climate conditions determine the sign (positive and negative) and magnitude of the sensitivity. Increases in LAI contribute a warming effect in cold regions, such as cold winter dry, cold summer dry, cold humid, and polar tundra climate zones and a cooling effect in arid regions, such as arid, temperate arid climate zones. In the arid regions, such as Western America, Central Asia and Western Austria, the cooling effect with LAI increase can be explained by the changes in the partitioning of surface 
energy simulated by CoLM. The increased LAI leads to a lower Qh and a larger Qle, indicating that, more energy is dissipated in the form of vapor which can result in a cooling effect. Nevertheless, the warming effect in the cold regions is confirmed by the partial correlation analysis that the sensitivity of SAT to LAI is closely related to that of the albedo, than to ET. This means that the changes of albedo associated with the increase in LAI are a crucial factor in influencing local climate. Similar findings have also been verified from other studies. For example, Lee et al. (2011) and Li et al. (2015) indicated that the presence of boreal forests induces a warming effect because of its lower albedo to absorb more radiation in comparison with the snow with higher albedo. Our results also show that temperature reduced significantly along with the snow fraction increase and the snow-induced cooling decreases significantly along with the LAI increase (Figure S8). It is implied that the LAI increase in boreal zones contributes to a net energy gain because of a reduction of albedo. And the warming effect is attributed to the Qh-dominated role in the dissipation of the extra energy, rather than the Qle because of the universal low temperature in the boreal regions. The results are further confirmed by the simulations of CoLM that $\mathrm{Qh}$ increased as a result of vegetation greening in these areas and induced a warm effect.

However, the CoLM simulated energy deficits do not agree well with the climatic sensitivity results in polar tundra and equatorial climate zones. We examined whether the CoLM realistically simulates the albedo and ET (Figure S9). The comparison indicates that the CoLM simulated ET is close to GLEAM and MTE ET. The CoLM simulated ET ranges from 168 mm/year to $1079 \mathrm{~mm} / \mathrm{year}$, and GLEAM and MTE ET range from $138 \mathrm{~mm} / \mathrm{year}$ to 1106 $\mathrm{mm} /$ year, and $164 \mathrm{~mm} /$ year to $1216 \mathrm{~mm} /$ year from among different climate zones, respectively. This comparison indicates that the unsupported climatic sensitivity results from the CoLM simulated energy budgets could not be attributed to the model ET. In contrast, there is an obvious underestimation of CoLM simulation of albedo compared to CLARA albedo. Especially in polar tundra climate zone, the CoLM albedo is only 0.21 which is much lower than the CLARA albedo 0.41. Therefore, the mismatch between CoLM simulated energy deficits and climatic sensitivity likely resulted from the simulated albedo. In the future, more work for the improvement and calibration of CoLM albedo are needed. 


\section{Conclusions}

In this study, we used remote sensing and re-analysis of datasets to access the climatic feedbacks of vegetation changes under different greenness gradients and climatological conditions. The potential biophysical mechanism was further investigated by using CoLM simulations. We conclude that the climatic feedbacks of vegetation to SAT are convergent and are associated with the increase in vegetation greenness. The findings are confirmed by the corresponding ET and albedo variations, together with the partitioning of surface energy. It suggests that the magnitude of climatic feedbacks of vegetation is mainly determined through the local energy budgets. In addition, the background climate conditions also play a key role in modulating these feedbacks. Our findings imply that under the background of increasing global vegetation greenness, the climatic feedbacks are getting weaker. This will be helpful to improving the understanding of the future climate change.

\section{Acknowledgements}

This work was financially supported by the Research Foundation - Flanders (FWO) (12T1419N), National Natural Science Foundation of China (Grant No. 31570536), the Chinese Academy of Sciences President's International Fellowship Initiative (Grant No. 2017VCA0002), and the Chinese Academy of Sciences - the World Academy of Sciences (CAS-TWAS)

President's Fellowship Programme (2017A8010210001).

\section{Conflict of interest}

The authors declare no conflict of interest in this work.

\section{References}

Alkama, R. and Cescatti, A. (2016). Biophysical climate impacts of recent changes in global forest cover. Science, 351: 600-604.

Anderson, R. G., Canadell, J. G., Randerson, J. T., Jackson, R. B., Hungate, B. A., Baldocchi, D. D., Ban-Weiss, G. A., Bonan, G. B., Caldeira, K. and Cao, L. (2011). Biophysical 
considerations in forestry for climate protection. Frontiers in Ecology and the Environment, 9: 174-182.

Bala, G., Caldeira, K., Wickett, M., Phillips, T., Lobell, D., Delire, C. and Mirin, A. (2007). Combined climate and carbon-cycle effects of large-scale deforestation. Proceedings of the National Academy of Sciences, 104: 6550-6555.

Ballantyne, A., Alden, C., Miller, J., Tans, P. and White, J. (2012). Increase in observed net carbon dioxide uptake by land and oceans during the past 50 years. Nature, 488: 70-72.

Bonan, G. B. 1996. Land surface model (LSM version 1.0) for ecological, hydrological, and atmospheric studies: Technical description and users guide. NCAR Technical Note T.N.417+STR. National Center for Atmospheric Research, Boulder, CO.

Bonan, G. B. (2008). Forests and climate change: forcings, feedbacks, and the climate benefits of forests. Science, 320: 1444-1449.

Bonan, G. B., Pollard, D. and Thompson, S. L. (1992). Effects of boreal forest vegetation on global climate. Nature, 359: 716-718.

Brun, L. J., Kanemasu, E. T. and Powers, W. L. (1972). Evapotranspiration from Soybean and Sorghum Fileds 1. Agronomy Journal, 64: 145-148.

Campolongo, F., Cariboni, J. and Saltelli, A. (2007). An effective screening design for sensitivity analysis of large models. Environmental Modelling \& Software, 22: 1509-1518.

Canadell, J. G. and Raupach, M. R. (2008). Managing forests for climate change mitigation. Science, 320: 1456-1457.

Dai, Y. and Zeng, Q. (1997). A land surface model (IAP94) for climate studies part I: Formulation and validation in off-line experiments. Advances in Atmospheric Sciences, 14: 433-460.

Dai, Y., Zeng, X., Dickinson, R. E., Baker, I., Bonan, G. B., Bosilovich, M. G., Denning, A. S., Dirmeyer, P. A., Houser, P. R. and Niu, G. (2003). The common land model. Bulletin of the American Meteorological Society, 84: 1013-1024.

Dickinson, E., Henderson-Sellers, A. and Kennedy, J. (1993). Biosphere-atmosphere transfer scheme (BATS) version 1e as coupled to the NCAR community climate model. NCAR Tech. Note TH-387+ STR.

Dickinson, R. E. and Henderson-Sellers, A. (1988). Modelling tropical deforestation: A study of GCM land - surface parametrizations. Quarterly Journal of the Royal Meteorological 
Society, 114: 439-462.

Enfield, D. B., Mestas - Nuñez, A. M. and Trimble, P. J. (2001). The Atlantic multidecadal oscillation and its relation to rainfall and river flows in the continental US. Geophysical Research Letters, 28: 2077-2080.

England, M. H., McGregor, S., Spence, P., Meehl, G. A., Timmermann, A., Cai, W., Gupta, A. S., McPhaden, M. J., Purich, A. and Santoso, A. (2014). Recent intensification of winddriven circulation in the Pacific and the ongoing warming hiatus. Nature Climate Change, 4: 222-227.

Field, C. B., Lobell, D. B., Peters, H. A. and Chiariello, N. R. (2007). Feedbacks of terrestrial ecosystems to climate change. Annu. Rev. Environ. Resour., 32: 1-29.

Forzieri, G., Alkama, R., Miralles, D. G. and Cescatti, A. (2017). Satellites reveal contrasting responses of regional climate to the widespread greening of Earth. Science, 356: 11801184.

Ge, Q., Zhang, X. and Zheng, J. (2014). Simulated effects of vegetation increase/decrease on temperature changes from 1982 to 2000 across the Eastern China. International Journal of Climatology, 34: 187-196.

Gibbard, S., Caldeira, K., Bala, G., Phillips, T. J. and Wickett, M. (2005). Climate effects of global land cover change. Geophysical Research Letters, 32 :L23705.

Global Modeling and Assimilation Office (GMAO). (2015), MERRA-2 instM_2d_gas_Nx: 2d,Monthly mean,Instantaneous,Single-Level,Assimilation,Aerosol Optical Depth Analysis V5.12.4, Greenbelt, MD, USA, Goddard Earth Sciences Data and Information Services Center (GES DISC).

Harris, I., Jones, P. D., Osborn, T. J. and Lister, D. H. (2014). Updated high - resolution grids of monthly climatic observations-the CRU TS3. 10 Dataset. International Journal of Climatology, 34: 623-642.

He, B., Huang, L., Liu, J., Wang, H., Lü, A., Jiang, W. and Chen, Z. (2017). The observed cooling effect of desert blooms based on high - resolution Moderate Resolution Imaging Spectroradiometer products. Earth and Space Science, 4: 247-256.

Hu, S. and Fedorov, A. V. (2017). The extreme El Niño of 2015-2016 and the end of global warming hiatus. Geophysical Research Letters, 44: 3816-3824.

Jeong, S.-J., Ho, C.-H., Kim, K.-Y., Kim, J., Jeong, J.-H. and Park, T.-W. (2010). Potential 
impact of vegetation feedback on European heat waves in a $2 \mathrm{xCO} 2$ climate. Climatic Change, 99: 625-635.

Jiang, B., Liang, S. and Yuan, W. (2015). Observational evidence for impacts of vegetation change on local surface climate over northern China using the Granger causality test. Journal of Geophysical Research: Biogeosciences, 120: 1-12.

Jing, C.-Q. and Li, L.-H. (2016). Simulating the energy and water fluxes from two alkaline desert ecosystems over Central Asia. Advances in Meteorology, 2016.

Jolliffe, I. T. (1982). A note on the use of principal components in regression. Journal of the Royal Statistical Society: Series C (Applied Statistics), 31: 300-303.

Jung, M., Reichstein, M., Ciais, P., Seneviratne, S. I., Sheffield, J., Goulden, M. L., Bonan, G., Cescatti, A., Chen, J. and De Jeu, R. (2010). Recent decline in the global land evapotranspiration trend due to limited moisture supply. Nature, 467: 951.

Kalnay, E., Kanamitsu, M., Kistler, R., Collins, W., Deaven, D., Gandin, L., Iredell, M., Saha, S., White, G. and Woollen, J. (1996). The NCEP/NCAR 40-year reanalysis project. Bulletin of the American Meteorological Society, 77: 437-472.

Karlsson, K., Anttila, K., Trentmann, J., Stengel, M., Fokke Meirink, J., Devasthale, A., Hanschmann, T., Kothe, S., Jääskeläinen, E. and Sedlar, J. 2017. CLARA-A2: CM SAF cLoud, Albedo and surface RAdiation dataset from AVHRR data-Edition 2, Satellite Application Facility on Climate Monitoring.

Klein, C., Bliefernicht, J., Heinzeller, D., Gessner, U., Klein, I. and Kunstmann, H. (2017). Feedback of observed interannual vegetation change: a regional climate model analysis for the West African monsoon. Climate Dynamics, 48: 2837-2858.

Kosaka, Y. and Xie, S.-P. (2013). Recent global-warming hiatus tied to equatorial Pacific surface cooling. Nature, 501: 403.

Kottek, M., Grieser, J., Beck, C., Rudolf, B. and Rubel, F. (2006). World map of the KöppenGeiger climate classification updated. Meteorologische Zeitschrift, 15: 259-263.

Lee, X., Goulden, M. L., Hollinger, D. Y., Barr, A., Black, T. A., Bohrer, G., Bracho, R., Drake, B., Goldstein, A. and Gu, L. (2011). Observed increase in local cooling effect of deforestation at higher latitudes. Nature, 479: 384.

Li, Y., Zhao, M., Motesharrei, S., Mu, Q., Kalnay, E. and Li, S. (2015). Local cooling and warming effects of forests based on satellite observations. Nature Communications, 6 : 
6603.

Liu, Z. (2012). Dynamics of interdecadal climate variability: A historical perspective. Journal of Climate, 25: 1963-1995.

Loranty, M. M., Berner, L. T., Goetz, S. J., Jin, Y. F. and Randerson, J. T. (2014). Vegetation controls on northern high latitude snow-albedo feedback: observations and CMIP5 model simulations. Global Change Biology, 20: 594-606.

Mao, J., Ribes, A., Yan, B., Shi, X., Thornton, P. E., Séférian, R., Ciais, P., Myneni, R. B., Douville, H. and Piao, S. (2016). Human-induced greening of the northern extratropical land surface. Nature Climate Change, 6: 959-963.

Martens, B., Gonzalez Miralles, D., Lievens, H., Van Der Schalie, R., De Jeu, R. A., FernándezPrieto, D., Beck, H. E., Dorigo, W. and Verhoest, N. (2017). GLEAM v3: Satellite-based land evaporation and root-zone soil moisture. Geoscientific Model Development, 10: 1903-1925.

McCarthy, G. D., Haigh, I. D., Hirschi, J. J.-M., Grist, J. P. and Smeed, D. A. (2015). Ocean impact on decadal Atlantic climate variability revealed by sea-level observations. Nature, 521: 508-510.

Miralles, D., Holmes, T., De Jeu, R., Gash, J., Meesters, A. and Dolman, A. (2011). Global landsurface evaporation estimated from satellite-based observations. Hydrology and Earth System Sciences, 15: 453.

Morris, M. D. (1991). Factorial sampling plans for preliminary computational experiments. Technometrics, 33: 161-174.

Naudts, K., Chen, Y., McGrath, M. J., Ryder, J., Valade, A., Otto, J. and Luyssaert, S. (2016). Europe's forest management did not mitigate climate warming. Science, 351: 597-600.

Pan, Y., Birdsey, R. A., Fang, J., Houghton, R., Kauppi, P. E., Kurz, W. A., Phillips, O. L., Shvidenko, A., Lewis, S. L. and Canadell, J. G. (2011). A large and persistent carbon sink in the world's forests. Science, 333: 988-993.

Pan, Y. H. and Oort, A. H. (1983). Global climate variations connected with sea surface temperature anomalies in the eastern equatorial Pacific Ocean for the 1958-73 period. Monthly Weather Review, 111: 1244-1258.

Pearson, R. G., Phillips, S. J., Loranty, M. M., Beck, P. S., Damoulas, T., Knight, S. J. and Goetz, S. J. (2013). Shifts in Arctic vegetation and associated feedbacks under climate change. 
Nature Climate Change, 3: 673-677.

Peng, S.-S., Piao, S., Zeng, Z., Ciais, P., Zhou, L., Li, L. Z., Myneni, R. B., Yin, Y. and Zeng, H. (2014). Afforestation in China cools local land surface temperature. Proceedings of the National Academy of Sciences, 111: 2915-2919.

Peng, S., Chen, A., Xu, L., Cao, C., Fang, J., Myneni, R. B., Pinzon, J. E., Tucker, C. J. and Piao, S. (2011). Recent change of vegetation growth trend in China. Environmental Research Letters, 6: 044027.

Piao, S., Wang, X., Ciais, P., Zhu, B., Wang, T. and Liu, J. (2011). Changes in satellite - derived vegetation growth trend in temperate and boreal Eurasia from 1982 to 2006. Global Change Biology, 17: 3228-3239.

Rayner, N., Parker, D. E., Horton, E., Folland, C. K., Alexander, L. V., Rowell, D., Kent, E. and Kaplan, A. (2003). Global analyses of sea surface temperature, sea ice, and night marine air temperature since the late nineteenth century. Journal of Geophysical Research: Atmospheres, 108: D14.

Richardson, A. D., Keenan, T. F., Migliavacca, M., Ryu, Y., Sonnentag, O. and Toomey, M. (2013). Climate change, phenology, and phenological control of vegetation feedbacks to the climate system. Agricultural and Forest Meteorology, 169: 156-173.

Schmidt, G. A., Shindell, D. T. and Tsigaridis, K. (2014). Reconciling warming trends. Nature Geoscience, 7: 158-160.

Seddon, A. W., Macias-Fauria, M., Long, P. R., Benz, D. and Willis, K. J. (2016). Sensitivity of global terrestrial ecosystems to climate variability. Nature, 531: 229-232.

Sheffield, J., Goteti, G. and Wood, E. F. (2006). Development of a 50-year high-resolution global dataset of meteorological forcings for land surface modeling. Journal of Climate, 19: 3088-3111.

Shen, M., Piao, S., Jeong, S.-J., Zhou, L., Zeng, Z., Ciais, P., Chen, D., Huang, M., Jin, C.-S. and Li, L. Z. (2015). Evaporative cooling over the Tibetan Plateau induced by vegetation growth. Proceedings of the National Academy of Sciences, 112: 9299-9304.

Snyder, P., Delire, C. and Foley, J. (2004). Evaluating the influence of different vegetation biomes on the global climate. Climate Dynamics, 23: 279-302.

Solomon, S., Daniel, J. S., Neely, R. R., Vernier, J.-P., Dutton, E. G. and Thomason, L. W. (2011). The persistently variable "background" stratospheric aerosol layer and global 
climate change. Science, 333: 866-870.

Wang, X., Piao, S., Ciais, P., Li, J., Friedlingstein, P., Koven, C. and Chen, A. (2011). Spring temperature change and its implication in the change of vegetation growth in North America from 1982 to 2006. Proceedings of the National Academy of Sciences, 108: 1240-1245.

Wickham, J. D., Wade, T. G. and Riitters, K. H. (2012). Comparison of cropland and forest surface temperatures across the conterminous United States. Agricultural and Forest Meteorology, 166: 137-143.

Winckler, J., Reick, C. H., Bright, R. M. and Pongratz, J. (2019). Importance of surface roughness for the local biogeophysical effects of deforestation. Journal of Geophysical Research: Atmospheres, 124: 8605-8618.

Woodward, F., Lomas, M. R. and Betts, R. A. (1998). Vegetation-climate feedbacks in a greenhouse world. Philosophical Transactions of the Royal Society of London. Series B: Biological Sciences, 353: 29-39.

Wu, X., Liu, H., Li, X., Piao, S., Ciais, P., Guo, W., Yin, Y., Poulter, B., Peng, C. and Viovy, N. (2017). Higher temperature variability reduces temperature sensitivity of vegetation growth in Northern Hemisphere. Geophysical Research Letters, 44: 6173-6181.

Yu, Q., Acheampong, M., Pu, R., Landry, S. M., Ji, W. and Dahigamuwa, T. (2018). Assessing effects of urban vegetation height on land surface temperature in the City of Tampa, Florida, USA. International Journal of Applied Earth Observation and Geoinformation, 73: $712-720$.

Yuan, X., Li, L., Chen, X. and Shi, H. (2015). Effects of precipitation intensity and temperature on NDVI-based grass change over Northern China during the period from 1982 to 2011. Remote Sensing, 7: 10164-10183.

Yuan, X., Wang, W., Cui, J., Meng, F., Kurban, A. and De Maeyer, P. (2017). Vegetation changes and land surface feedbacks drive shifts in local temperatures over Central Asia. Scientific Reports, 7: 1-8.

Zampieri, M., Toreti, A., Schindler, A., Scoccimarro, E. and Gualdi, S. (2017). Atlantic multidecadal oscillation influence on weather regimes over Europe and the Mediterranean in spring and summer. Global and Planetary Change, 151: 92-100.

Zeng, Z., Piao, S., Li, L. Z., Zhou, L., Ciais, P., Wang, T., Li, Y., Lian, X., Wood, E. F. and 
Friedlingstein, P. (2017). Climate mitigation from vegetation biophysical feedbacks during the past three decades. Nature Climate Change, 7: 432-436.

Zhang, M., Lee, X., Yu, G., Han, S., Wang, H., Yan, J., Zhang, Y., Li, Y., Ohta, T. and Hirano, T. (2014). Response of surface air temperature to small-scale land clearing across latitudes. Environmental Research Letters, 9: 034002.

Zhang, X., Tang, Q., Zheng, J. and Ge, Q. (2013). Warming/cooling effects of cropland greenness changes during 1982-2006 in the North China Plain. Environmental Research Letters, 8: 024038.

Zhao, K. and Jackson, R. B. (2014). Biophysical forcings of land - use changes from potential forestry activities in North America. Ecological Monographs, 84: 329-353.

Zhou, C. and Wang, K. (2016). Land surface temperature over global deserts: Means, variability, and trends. Journal of Geophysical Research: Atmospheres, 121: 344-357.

Zhou, Y., Zhang, L., Fensholt, R., Wang, K., Vitkovskaya, I. and Tian, F. (2015). Climate contributions to vegetation variations in central Asian drylands: Pre-and post-USSR collapse. Remote Sensing, 7: 2449-2470.

Zhu, Z., Bi, J., Pan, Y., Ganguly, S., Anav, A., Xu, L., Samanta, A., Piao, S., Nemani, R. and Myneni, R. (2013). Global data sets of vegetation leaf area index (LAI) $3 g$ and fraction of photosynthetically active radiation (FPAR) $3 \mathrm{~g}$ derived from global inventory modeling and mapping studies (GIMMS) normalized difference vegetation index (NDVI3g) for the period 1981 to 2011. Remote Sensing, 5: 927-948.

Zhu, Z., Piao, S., Lian, X., Myneni, R. B., Peng, S. and Yang, H. (2017). Attribution of seasonal leaf area index trends in the northern latitudes with "optimally" integrated ecosystem models. Global Change Biology, 23: 4798-4813.

Zhu, Z., Piao, S., Myneni, R. B., Huang, M., Zeng, Z., Canadell, J. G., Ciais, P., Sitch, S., Friedlingstein, P. and Arneth, A. (2016). Greening of the Earth and its drivers. Nature Climate Change, 6: 791-795. 

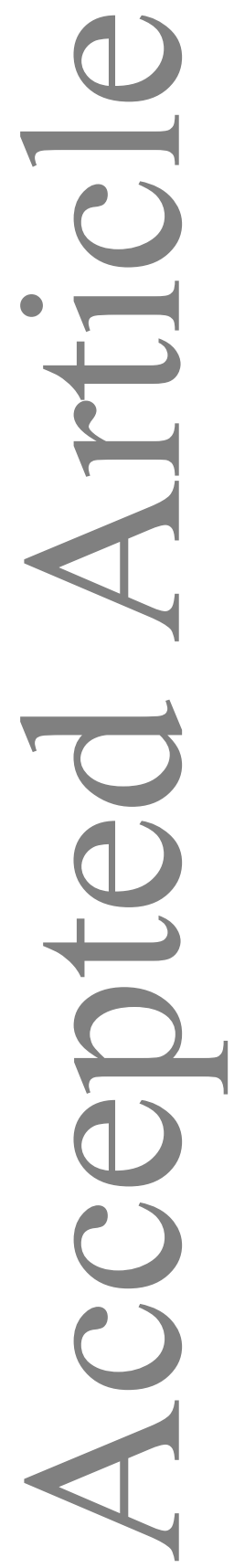
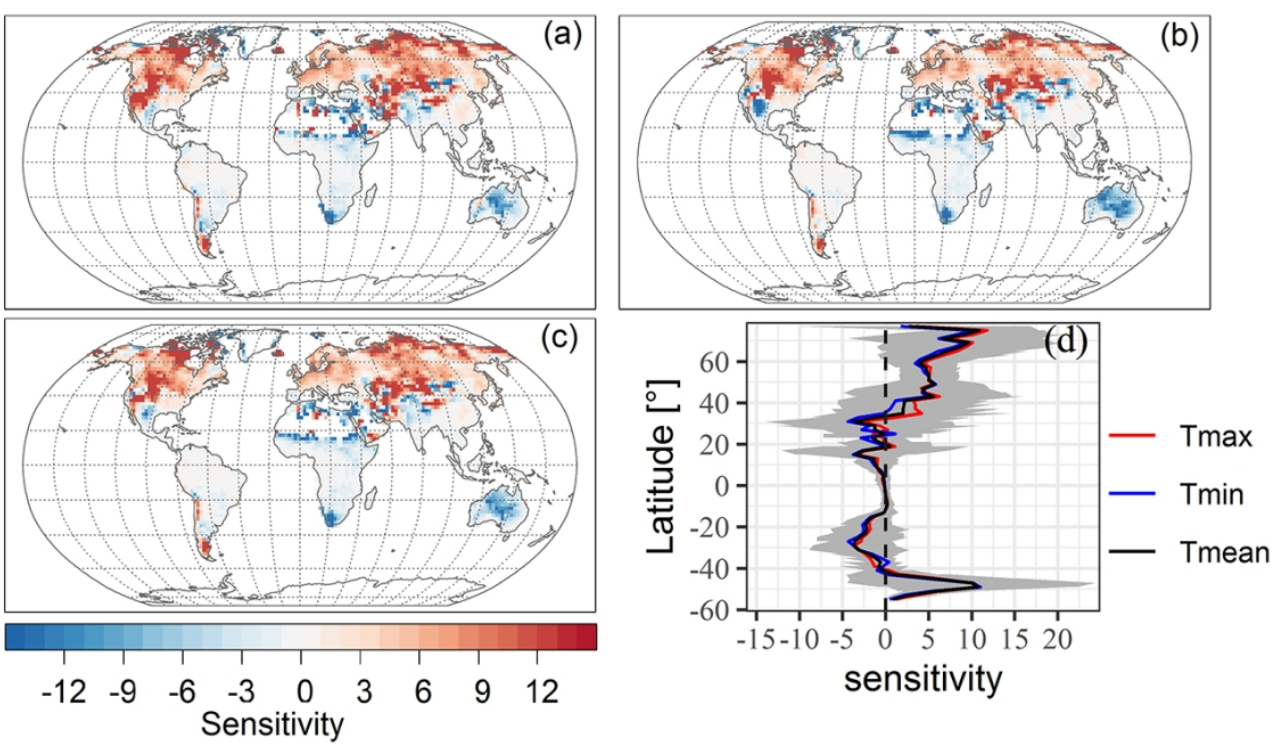

Figure 1. Sensitivities of surface air temperature (SAT) to leaf area index (LAI). Spatial map of the interannual sensitivities of maximum, minimum, and mean daily SAT ( $T_{\max }, T_{\min }, T_{\text {mean }}$ ) to LAI (a-c); Latitudinal profiles of the sensitivities (d).

$$
109 \times 64 \mathrm{~mm}(300 \times 300 \mathrm{DPI})
$$




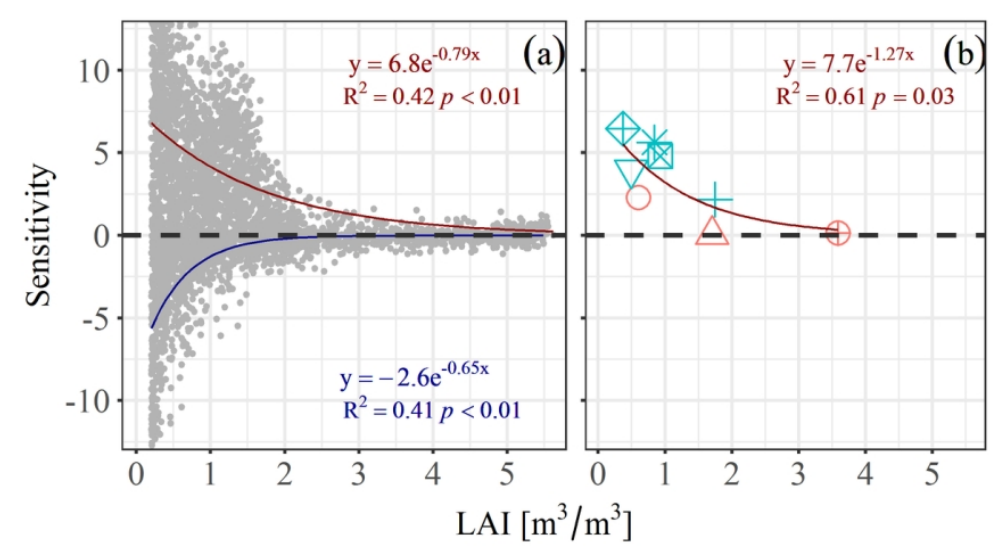

\section{Climate}

Arid region

$\triangle$ Temperate arid

+ Temperate humid

$\nabla$ Cold summer dry

Cold winner dry

* Cold humid

$\leftrightarrow$ Polar tundra

$\oplus$ Equatorial

\section{Sign}

Negative

Positive

Figure 2. Variations in climatic sensitivities of $T_{\text {mean }}$ associated with LAI. Sensitivity values across vegetation greenness gradients (a); mean sensitivity values in different climate zones (b). The fitted lines in this figure are the exponential regression lines.

$135 \times 62 \mathrm{~mm}(300 \times 300 \mathrm{DPI})$ 

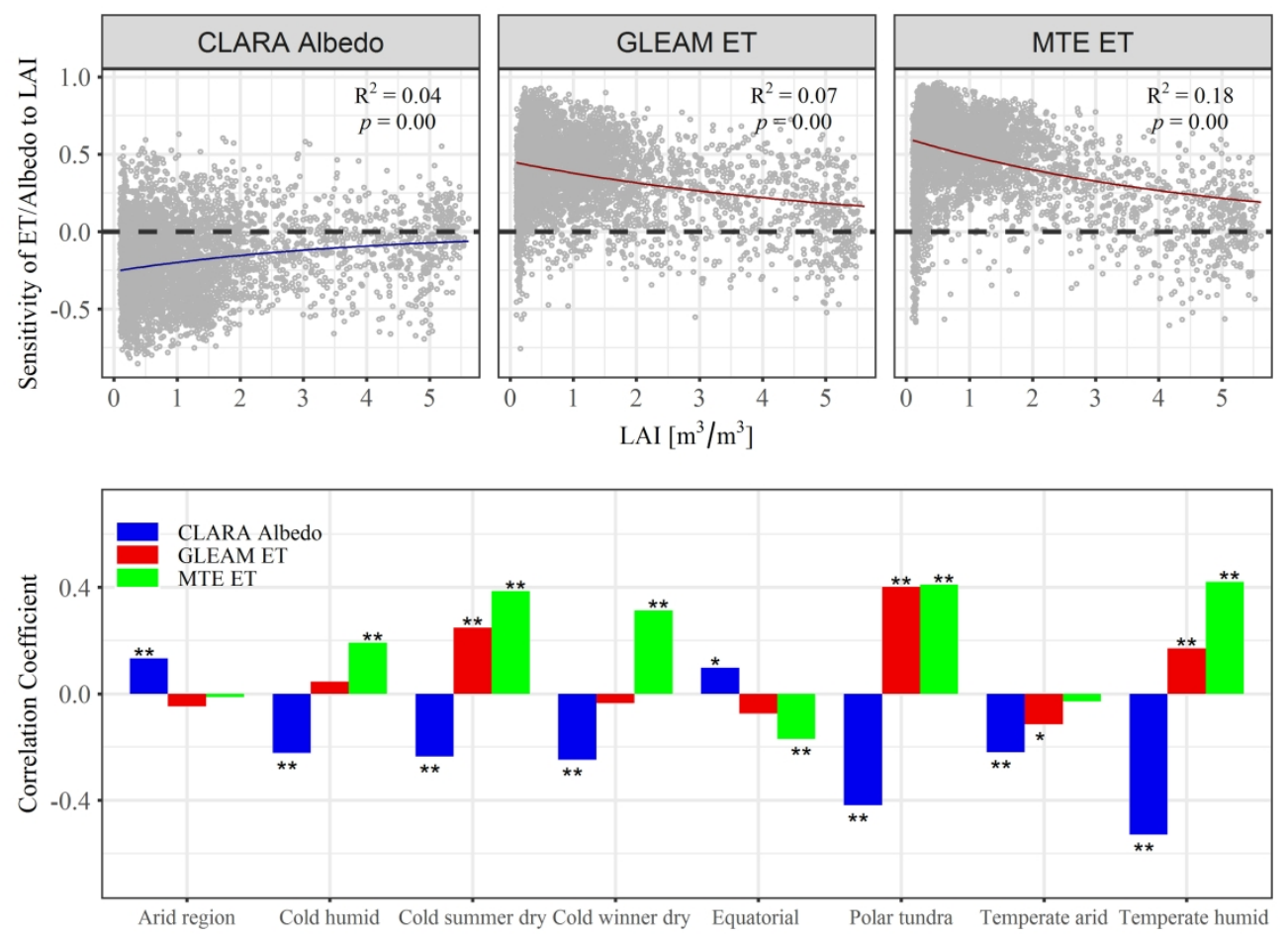

Figure 4. The variations of the sensitivities of albedo and ET to LAI changes across LAI gradients (upper panel), and the partial correlation coefficients between the Tmean sensitivity and the sensitivity of ET/albedo to LAI (i.e., $\Delta \mathrm{ETT} / \Delta \mathrm{LAI}, \Delta$ albedo/ $\Delta \mathrm{LAI}$ ) across multiple climate zones (lower panel). The values of $\Delta \mathrm{ET} / \Delta \mathrm{LAI}$ and $\Delta$ albedo/ $\Delta$ LAI are rescaled into a range of $[-1,1]$

$$
142 \times 105 \mathrm{~mm}(600 \times 600 \text { DPI) }
$$



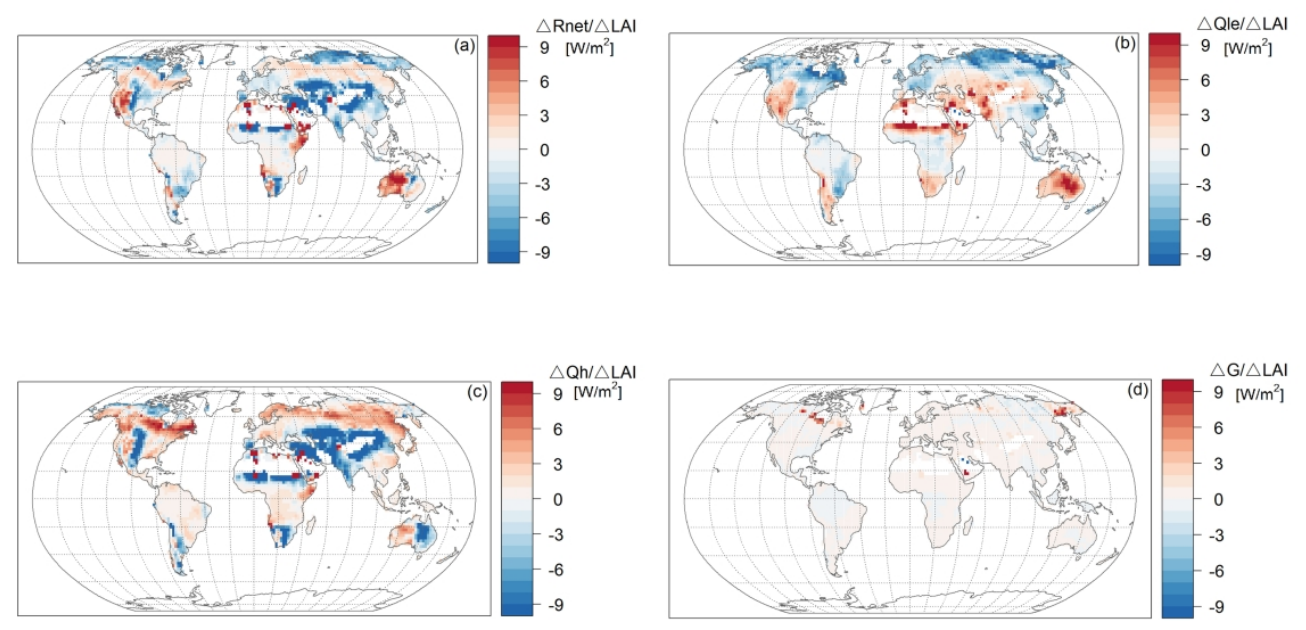

Figure 5. Spatial map of sensitivities of energy fluxes to LAI changes. Net radiation (a), Latent (Qle) (b), sensible $(Q h)(c)$, and ground heat fluxes $(G)(d)$.

$$
253 \times 136 \mathrm{~mm}(300 \times 300 \mathrm{DPI})
$$


